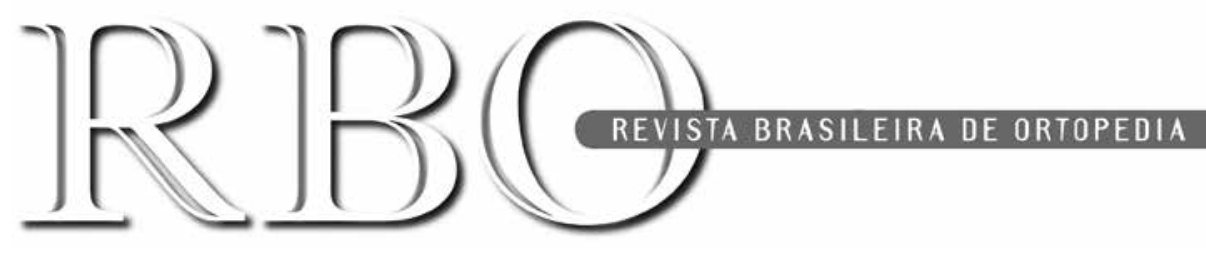

\title{
Editorial
}

\section{Latin American Journal of Orthopedics and Traumatology}

On May 16, 17 and 18, under the sponsorship of the Colombian Society of Orthopedics, a meeting was held in Cartagena bringing together the editors of the following orthopedics and traumatology journals in Latin America: Acta Mexicana, Revista Brasileira de Ortopedia, Revista Venezuelana, Revista Chilena, Revista Dominicana, Revista Mexicana, Revista Peruana, Revista Argentina and Revista Colombiana and a representative from the Spanish Society of Orthopedics and Traumatology. At this meeting, the creation of the Revista Latino-Americana de Ortopedia e Traumatologia (Latin American Journal of Orthopedics and Traumatology; RLAOT) was discussed.

The meeting concluded with the following decisions:

1) The RLAOT was founded, and will have an electronic (e-journal) format;

2) Its main office will be at the SLAOT, which is currently administratively based in Colombia;

3) Three editors were chosen: Gilberto Camanho, from Brazil, editor-in-chief; Felipe Gomes, from Mexico, second editor; and Francisco Forriol, from Spain, third editor;

4) Dr. Juan Manuel Herrera, from Colombia, was chosen as the editor for relations with SLAOT; 
5) During the first year, the RLAOT will have four quarterly issues, each composed of 10 studies that have already been published in the journals of the societies that make up the RLAOT, selected by the editors of the RLAOT. These studies will come from a database of papers sent in by the editors of these journals. For them to form part of the RLAOT, they will send a minimum of four papers, structured in accordance with international norms, as furnished by Acta Mexicana;

6) The studies will be written and published in the originating language and will also be translated and published in English;

7) Editorial support will be provided by Acta Mexicana, and will be backed up by SLAOT;

8) Considering that Acta Mexicana is indexed in Medline, it was established that this journal will edit studies by authors in the journals that make up the RLAOT who wish to publish in an indexed journal, provided that the study is in the correct format and has been approved by the editor of the originating journal, without the need to go through submission to the editorial board of Acta Mexicana;

9) The editorial boards of the journals that make up the RLAOT will be increased to include the editors of the Latin American journals, so that publication between Latin American societies will become possible; and

10) The autonomy and editorial policies of the journals of each society that makes up the RLAOT will continue to be respected.

In this manner, we expected to be commencing a new era in our relationships within Latin America, with extension to Spain and Portugal. There will also be a new experience with an e-journal, which we believe to be the future of scientific publications.

Studies to be sent to the RLAOT will be selected by the Editorial Board. Those that are thus selected will only be published in the RLAOT with expressed authorization from the authors.

We are taking our place within Latin American orthopedics.

Hasta la vista! 